\title{
LA INTRANSMISIBILIDAD DE LA OBLIGACIÓN ALIMENTICIA.
}

\author{
THE INTRANSMISSIBILITY OF THE MAINTENANCE \\ OBLIGATION.
}

MURIEL SABIONCELLO SOTO*

\section{Resumen}

Este trabajo plantea que la obligación alimenticia, como consecuencia de su carácter personalísimo, es intransmisible. El problema surge del hecho que, si bien el Código Civil en su artículo 334 expresa claramente que el derecho de alimentos no puede transmitirse por causa de muerte, no existe una norma semejante que resuelva si la obligación alimenticia es o no transmisible, por lo que es necesario que esta cuestión sea resuelta, toda vez que la determinación de la naturaleza transmisible o intransmisible de la obligación alimenticia incide directamente en la sucesión del obligado a otorgar alimentos por una sentencia judicial o un equivalente jurisdiccional.

\section{Palabras Claves}

Obligación alimenticia. Personalísima. Intransmisibilidad. Alimentante. Alimentario.

Artículo recibido para su evaluación el 10 de junio de 2021, y aprobado para su publicación el 25 de julio de 2021.

"Profesora auxiliar de Derecho Civil de la Escuela de Derecho de la Universidad de Valparaíso. Email: muriel.sabioncello@uv.cl 


\begin{abstract}
This article establishes that maintenance obligation, as a consequence of its highly personal character, is non-transferable. However this causes a problem that emerges from the fact that, although the Civil Code clearly states, in its article 334, that the right to maintenance cannot be transmitted due to death, there is no similar rule that solves whether the maintenance obligation is transferable or not. Thus, it becomes necessary to resolve this issue whenever the determination of the transferable or non-transferable nature of the maintenance obligation directly affects the succession of the person obliged to grant maintenance by a court statement or a jurisdictional equivalent.
\end{abstract}

\title{
Keywords
}

Maintenance obligation. Very personal. Intransmissibility. Food creditor. Food debtor.

\section{INTRODUCCIÓN.}

El artículo 334 de nuestro Código Civil expresa que "el derecho de pedir alimentos no puede transmitirse por causa de muerte, ni venderse o cederse de modo alguno, ni renunciarse". A partir de esta norma, la doctrina nacional concluye cuáles son las más importantes características del derecho de alimentos: que es intransmisible, incomerciable, imprescriptible, irrenunciable y personalísimo ${ }^{123}$. En consecuencia, el derecho de alimentos, sin duda, es un derecho personalísimo e intransmisible. La cuestión es, si la obligación alimenticia también lo es, ya que no existe norma semejante a la del artículo 334, respecto de la obligación correlativa. De ser la obligación alimenticia transmisible, ella sería adquirida por el modo de adquirir sucesión por causa de muerte por los herederos del alimentente y se segurían devengando con posterioridad al fallecimiento del obligado a

1 VODANOVIC HAKLIKA, Antonio. Derecho de alimentos. Lexis Nexis. Santiago, 2004. Pp. 195, 202.

2 GARRIDO CHACANA, Carlos. Derecho de Alimentos. Editorial Metropolitana. Santiago, 2014. pág. 84.

3 ORREGO ACUÑA, Juan Andrés. Los alimentos en el Derecho Chileno. Editorial Metropolitana. Santiago, 2009. pág.33. 
prestar alimentos. Si no es transmisible, entoces se extinguiría al momento de la muerte del obligado a otorgar alimentos.

\section{EL CARÁCTER PERSONALÍSIMO DE LA OBLIGACIÓN ALIMENTICIA.}

Afirmamos que la obligación de alimentos es personalísima y fundamos nuestra aseveración en los siguientes argumentos:

I.- El tenor del artículo 321 del Código Civil. Esta norma en su encabezado señala: "Se deben alimentos...." para luego enumerar al cónyuge y otros parientes consanguíneos. Es decir, siempre, con excepción del No. 5 del artículo 321, que otorga derecho de alimentos al que hizo una donación cuantiosa, el deudor y acreedor de alimentos, alimentante y alimentario, serán cónyuges o parientes entre sí. El título que habilita para demandar alimentos, la causa o más bien el fundamento de esta obligación, que no debemos olvidar, reconoce como fuente a la ley, es precisamente las relaciones de familia enumeradas en el artículo 321. Dicho negativamente, si dos personas no tienen el vínculo familiar establecido en el enunciado normativo, uno no tendrá derecho de reclamar alimentos respecto del otro y éste no tendrá obligación de pagarlos. Por ejemplo, los cónyuges. Declarado el divorcio mediante sentencia firme o ejecutoriada, el cónyuge deudor deja de estar obligado a dar alimentos al cónyuge acreedor. La anterior afirmación nos lleva a concluir que los alimentos, ya sea desde su faz activa como pasiva, reconoce su causa en el parentesco y en el matrimonio, es decir en el estado civil del alimentante y del alimentario, salva la excepción del $\mathrm{N}^{\circ} 5$ del artículo 321.

El estado civil se define en el artículo 304 del Código Civil como "la calidad de un individuo, en cuanto le habilita para ejercer ciertos derechos o contraer determinadas obligaciones civiles". Esta definición ha sido criticada siendo más aceptada aquélla doctrinaria de Manuel Somarriva. "Lugar permanente de una persona dentro de la sociedad que depende principalmente de sus relaciones de familia y que lo habilita para ejercer ciertos derechos y contraer ciertas obligaciones civiles"4. Semejante es la definición de Máximo Pacheco: "La posición permanente que una persona jurídica individual ocupa en la sociedad, en orden a sus relaciones de familia, que le confiere e impone determinados derechos y obligaciones

4 SOMARRIVA UNDURRAGA Manuel, Derecho de Familia. Editorial Nascimento. Santiago, 1963. pag. 584. 
civiles"5. El estado civil, a su vez es un atributo de la personalidad, es decir, "una serie de cualidades, propiedades o prerrogativas que pertenecen a las personas por el solo hecho de serlo"6. En consecuencia, los atributos de la personalidad surgen con el principio de la existencia legal de las personas y se extinguen con su fin.

Según se desprende de las definiciones dadas, el estado civil impone obligaciones, -la mayoría, más bien deberes- y entre ellas la obligación alimenticia. No obstante, el estado civil es un atributo de la personalidad y como tal se extingue con el fin de la personalidad jurídica, esto es con la muerte de una persona natural. Si se extingue la persona se extingue el atributo de la personalidad, el estado civil y en consecuencia, todos sus efectos, es decir los derechos y obligaciones que ese estado civil confería e imponía. Si se deja de ser familiar o pariente, también se extingue su consecuencia, el derecho, deber u obligación de carácter personalísimos que encuentran su causa en dicha relación de familia o parentesco, entre ellos el derecho y la obligación de alimentos, la patria potestad, la autoridad paterna, los derechos y deberes personales del matrimonio, etc.

La obligación alimenticia es intuito personae nace, beneficia y obliga a determinadas personas entre sí porque ellas tienen la calidad de cónyuges o los parentescos señalados en el artículo 321 y reúnen, además los otros requisitos señalados en la ley. En consecuencia, cuando fallece el alimentante la obligación alimenticia se extingue por las razones expuestas.

De la misma opinión es el colombiano Suárez Franco, quien expresa que "es evidente que los alimentos que se deben por ley se conceden intuito personae, tanto del alimentante como del alimentario; y ello se explica por la naturaleza misma de la obligación; quiere esto decir que cuando uno de los miembros de la relación de familia fallece, cesa la pensión alimenticia. Puede suceder que la muerte del alimentante o del alimentario de origen a una nueva obligación alimentaria entre otras personas, pero sí lo que es un hecho incuestionable es que la muerte del alimentante o del alimetario pone fin a la obligación alimenticia" 7 .

Interesante es el argumento esgrimido por la Corte de Apelaciones de Santiago en cuanto señala que los herederos del alimentante no están enumerados en el artículo 321 del Código Civil: “....Que debe entenderse,

5 PACHECO, Máximo. Introducción al Derecho, Editorial Jurídica del Chile. Santiago. 1976, pag. 121.

6 Ibídem. pag.113.

7 SUAREZ FRANCO, Roberto, Derecho de Sucesiones, Temis. Bogotá. 1989, pag. 306. 
como sostiene el Juez de Grado, que la obligación de alimentos debidos por el causante, no es trasmisible a sus herederos por tratarse de derechos personalísimos; la situación descrita, resulta acorde a lo dispuesto en el artículo 321 del Código Civil que no establecen a los herederos dentro de las personas obligadas al pago"s.

Este tema está íntimamente relacionado con la intransmisibilidad de la obligación alimenticia.

\section{LA INTRANSMISIBILIDAD DE LA OBLIGACIÓN ALIMENTICIA.}

El problema de la transmisibilidad de la obligación alimenticia tiene dos variantes: una es determinar si fallecida una persona obligada a dar alimentos, ya sea por sentencia judicial o por un equivalente jurisdiccional, la obligación así establecida se trasmite a sus herederos por aplicación del artículo 1097 del Código Civil, es decir, si éstos siguen obligados a pagar las pensiones alimenticias que se devenguen con posterioridad a su muerte. El segundo aspecto relacionado con este mismo tema, es si una persona que tiene derecho de demandar alimentos a otra, que fallece, puede demandar a los herederos del causante.

Nos ocuparemos de la primera situación planteada porque solo ella es relevante para este trabajo.

Desde que Carlos Aguirre Vargas planteara, en el siglo XIX, que la obligación alimenticia es trasmisible, este tema se ha discutido en doctrina. Para Aguirre Vargas la obligación alimenticia era trasmisible en ambos aspectos. Lo desprende en primer lugar del tenor del artículo 332 del Código Civil. "Si se deben por toda la vida del alimentario, claro es que fallecido el alimentante, seguirán debiéndose por sus herederos". Agregaba: "Esto lo corrobora el artículo 951 al decir que el título es universal cuando se sucede al difunto en todos sus bienes, derechos y obligaciones trasmisibles....; lo repite el art. 1097 y lo consagran muchas otras disposicioes de nuestro derecho al ocuparse de las responsabilidades propias de los herederos". 9 También es partidario de la transmisibilidad de la obligación alimenticia Pablo Rodríguez quien afirma que la intransmisibilidad "contraviene

8 "Sentencia de la Octava Sala de la Corte de Apelaciones de Santiago, 22.6.2010. Recurso 3237/2009

9 AGUIRRE VARGAS, Carlos. Obras jurídicas. Imprenta Gutemberg. Santiago, 1891. pag. 75 . 
el espíritu y la letra de la ley" "atendido el carácter asistencial de los alimentos y su hondo contenido social". Para él "resulta impensable que quien puede reclamar en vida una pensión alimenticia (y la ha reclamado), pierda su derecho a percibirla, no obstante que los herederos son los continuadores de la personalidad del causante (artículo 1097) y como tales, titulares de sus bienes y de sus obligaciones" ${ }^{10}$. Para los profesores Domínguez, en cambio, la obligación alimenticia es intransmisible, tanto en cuanto a la imposibilidad de demandar a los herederos del alimentante ahora fallecido, como a la obligación de los mismos de seguir pagando una pensión de alimentos a que había sido obligado por sentencia judicial o por un equivalente jurisdiccional el de cujus. Fundan su opinión en que el deber alimenticio es personalísimo y no transmisible y en el hecho que el proyecto de 1853 era explícito en ordenar que la obligación alimenticia era trasmisible a los herederos del alimentante, pero la idea de transmisibilidad no pasó al Código, que nada dice al respecto ${ }^{11}$. Luis Claro Solar señala respecto de la misma cuestión, escuetamente: " se trata de obligaciones personales del difunto que no se trasmiten a los herederos...." 12 . En otra parte de su obra esgrime como fundamento de la intransmisibilidad precisamente el hecho que sean asignaciones forzosas. "Porque son tales, no se trasmiten a los herederos"13. Fabián Elorriaga es de la misma opinión. Para él: "La regla general es que los alimentos que se deben por ley constituyan una baja general de la herencia, según lo señalado en al artículo $959 \mathrm{~N}^{\circ} 4$. Asimismo, señala el artículo 1168 , en su primera parte, que los alimentos que el difuto ha debido por ley a ciertas personas, gravan la masa hereditaria. Esto demuestra que la obligación alimenticia es intransmisible, dado que ella no pasa a los herederos del de cujus, sino que la obligación grava la masa hereditaria" ${ }^{14}$. El profesor Alejandro Guzmán afirma que

10 RODRIGUEZ GREZ, Pablo. Instituciones de Derecho sucesorio. Tomos I, Editorial Jurídica de Chile. Santiago, 2002. pág. 287.

11 DOMINGUEZ BENAVENTE, Ramón, DOMÍNGUEZ ÁGUILA, Ramón. Derecho sucesorio. Tomo II. Editorial Jurídica de Chile. Santiago, 1998. Pags.905 y 906

12 CLARO SOLAR, Luis. Explicaciones de Derecho Civil y Comparado. Tomo XV, "De la sucesión por causa de muerte" Santiago, 1942. pag. 274

13 CLARO SOLAR, Luis. Explicaciones de Derecho Civil y Comparado. Tomo XIII, "De la sucesión por causa de muerte” Santiago, 1940. Pág. 165

14 ELORRIAGA DE BONIS, Fabián, Derecho Sucesorio. Abelardo Perrot, Legal Publishing, Santiago, 2010. pag. 395. 
"la obligación de dar alimentos constituida en vida del alimentante por sentencia o transacción es transmisible" $" 15$.

Pero existen muchas otras razones para afirmar que la obligación alimenticia es intransmisible:

a. El derecho de alimentos y la correlativa obligación alimenticia es, salvo una excepción de escasa aplicación práctica (la del No. 5 del artículo 321 del Código Civil) un efecto del estado civil. Emanan del parentesco legalmente determinado o de la relación matrimonial que existe entre alimentante y alimentario. Los derechos y obligaciones que surgen del estado civil son personalísimos y como tal intransmisibles. Se extinguen con el fin de la existencia legal de las personas. En consecuencia, no es posible aplicar el artículo 1097 del Código Civil a los alimentos que se deben por ley a ciertas personas, porque dicha norma precisamente ser refiere a las obligaciones transmisibles de un causante y la obligación alimenticia no lo es. Los herederos no representan al causante en esta obligación. Es tan ilógico como afirmar que los herederos de un causante que tenía hijos menores de edad serán también titulares de la patria potestad o de la autoridad paterna respecto de esos hijos porque la patria potestad y la autoridad paterna también son efectos del estado civil, personalísimos que se extinguen con la muerte de su titular.

b. En cuanto al argumento de Pablo Rodríguez, que afirma que los alimentos tienen un contenido social y carácter asistencial y por eso son transmisibles: es indudable que los alimentos tienen un contenido asistencial, pero esta especial naturaleza de los alimentos no se ve en absoluto vulnerada por la intransmisibilidad de la obligación alimenticia, ya que en nuestro ordenamiento existen mecanismos que garantizan, incluso más eficientemente, el derecho del alimentario, por cuanto, de conformidad al artículo 326 inciso final, en relación con el artículo 232 ambos del Código Civil, y el artículo $3^{\mathrm{a}}$ inciso final de la ley 14.908, cuando el obligado a pagar alimentos falta o es insuficiente, se debe recurrir al obligado de grado siguiente. Además, no existe una relación lógica entre el carácter asistencial y contenido social del derecho de alimentos y su transmisibilidad. No por tener la primera calidad, debe concluirse lo segundo en contra de lo dispuesto en los artículos 951 y 1097 del Código. Además, si ha quedado

15 GUZMAN BRITO, Alejandro. La doble naturaleza de deuda hereditaria y asignación hereditaria forzosa de los alimentos debidos por ley a ciertas personas. En Revista Chilena de Derecho, Vol 35, N². 2008 pág.318. 
establecido que la obligación alimenticia es personalísima, el carácter asistencial de los alimentos no puede transformarla en transmisible.

c. La norma del artículo 332 del Código Civil, que es el argumento de Carlos Aguirre Vargas para pronunciarse ya en el siglo XIX, a favor de la transmisibilidad de la obligación alimenticia, establece que los alimentos que se deben por ley se entienden concedidos para toda la vida del alimentario, continuando las circunstancias que legitimaron la demanda. Las circunstancias que legitimaron la demanda son los requisitos de la obligación alimenticia. Sin duda que la existencia del título que habilita para reclamar alimentos es una de las circunstancias que legitima la demanda. Fallecido el alimentante, obviamente desaparece una circunstancia esencial: el título para tener derecho a alimentos, de modo que no es efectivo que se mantengan las circunstancias que legitimaron la demanda, por lo que dejan de deberse los alimentos.

d. La tesis de la intransmisibilidad ha sido recogida por la Corte Suprema. Los argumentos del máximo tribunal, señalados en los considerandos cuarto y octavo de la sentencia que desecha un recurso de casación en el fondo interpuesto en contra de una que negó lugar a una demanda de aumento de pensión de alimentos ejercida en contra de los herederos del alimentante premuerto son, en síntesis, : "Que la obligación alimenticia tiene una naturaleza especial, pues se trata de una acción personalísima que, como tal presenta caracteres propios, entre los cuales se encuentra y tiene interés en el caso sub lite, el de su intransmisibilidad"..... "Existe, además, para reafirmar esa conclusión un antecedente contenido en la historia fidedigna de la ley. En efecto en el proyecto de 1853, el artículo 371 preveía expresamente que la obligación de proporcionar alimentos, se transmitía a los herederos y legatarios del que debió prestarlos, y esta disposición fue suprimida por la Comisión Revisora, teniendo en consideración que en el Derecho Francés ésta era intransmisible y procurando evitar los problemas prácticos de aplicación que se podrían producir". "Que, en efecto, la procedencia de la acción de alimentos, así como la que pretende su revisión y/o modificación, requieren del análisis de ciertos presupuestos como la existencia de las figuras del alimentario y alimentante, con el título legal que los habilite en estas categorías, el estado de necesidad del primero que legitime la procedencia de los alimentos y la situación o capacidad de 
proporcionarlos, lo que no se verifica en la especie, atendida la muerte del padre alimentante ${ }^{16}$.

e. El Proyecto Inédito establecía expresamente, en el artículo $1325^{1718}$, por regla general, la transmisibilidad de la obligación alimenticia, exceptuándose de ella los ascendientes legítimos y los descendientes legítimos, cuando, fallecida aquella persona de quien recibía alimentos forzosos, tuvieren derecho, según el inciso primero del mismo artículo, para exigirlos a otra. En ese caso, perdían su acción contra los herederos de la primera. En consecuencia, no tenían derecho a la asignación alimenticia forzosa, sino que debían demandar alimentos de conformidad a las normas del Libro I, tal como hoy se establece en el artículo 326, en relación con el 332 del Código Civil y artículo $3^{\circ}$, inciso final de la ley 14.908 .

Es decir, en esta hipótesis la obligación también era intransmisible y no surgía el derecho a la asignación. En el Código de 1855 no se establece que la obligación alimenticia sea transmisible y regula en el inciso final del artículo $326^{19}$, una solución semejante a la que el inciso segundo del artículo 1325 del proyecto inédito establecía como excepción cuando la obligación alimenticia no era trasmisible: en caso de insuficiencia de todos los obligados por el título preferente, debe recurrirse al otro.

Si el Código Civil asigna a la falta del obligado por el título preferente, debiendo entender que falta el obligado cuando fallece, el efecto que el Proyecto Inédito establecía cuando la obligación no era transmisible, debemos concluir que la obligación alimenticia no es transmisible.

\section{IV.FALTAO EXTINCIÓN DELTÍTULO PARA PEDIRALIMENTOS.}

Otro aspecto que es necesario abordar en relación con la extinción de la obligación alimenticia entre vivos, es establecer qué sucede con ella cuando termina la existencia legal de uno de los sujetos de la obligación

16 "Sentencia de la Cuarta Sala de la Corte Suprema, 27.1.2011. Recurso 6424/2010 "Rojas Palma con Hammer Krawczyk".

17 "La obligacion de prestar alimentos no se trasmite a los herederos sino en favor de las personas designadas en los números 2, 3, 4, 5, 6, 7, 9 i 10 del artículo 360.

Las designadas en los números 2 i 3 , que, fallecida aquella de quien recibian alimentos forzosos, tuvieren derecho, según el precedente inciso, para exijirlos a otra, perderán su acción contra los herederos de la primera"

18 BELLO, Andrés, Obras completas. Santiago, Editorial Nascimento, 1932. Pag. 300.

19 En armonía con el artículo 232 del Código Civil y el inciso final del artículo $3^{\circ}$ de la Ley 14.908 . 
alimenticia: el alimentante respecto de quien se tenía título que habilitaba para demandar alimentos, y estos habían sido establecidos por sentencia firme o a través de un equivalente jurisdiccional. Se ha conceptualizado título como "Origen o fundamento jurídico de un derecho u obligación y demostración auténtica del mismo" 20 . Couture lo define como calidad o condición en que se detenta una cosa o se ejerce un derecho ${ }^{21}$. También se ha dicho que es un antecedente jurídico que habilita para la adquisición o es la causa inmediata de un derecho o de una obligación. Este título puede ser la ley, un acto jurídico, un parentesco, etc. En consecuencia, cuando el artículo 326 del Código Civil se refiere a los títulos que pueda reunir un alimentario para demandar alimentos, se refiere a cada una de las relaciones de familia enumeradas en el artículo 321 , sin perjuicio del $\mathrm{N}^{\circ} 5$ del mismo artículo. Es decir, son títulos el de cónyuge, el de descendiente, el de ascendiente, el de hermano y el de donante. Porque son precisamente dichas calidades las que constituyen el antecedente jurídico que habilita para la adquisición del derecho de alimentos o es la causa inmediata del mismo.

Ahora bien, siendo requisito de la obligación alimenticia, entre otros, la existencia de un título legal que habilita al alimentario para demandar alimentos, no cabe sino concluir que muerto el alimentante suceden dos cosas: la obligación alimenticia pierde uno de los sujetos del vínculo obligacional: el deudor y, además, el alimentario ya no tiene título para exigir alimentos a ese obligado. "Existiendo un derecho, existe una obligación y viceversa; si hay un obligado es porque hay un titular que puede exigir esa obligación y viceversa. Dando nombre a los sujetos del vínculo: si hay un deudor es porque hay un acreedor y viceversa" ${ }^{22}$. En consecuencia, siendo requisito esencial de la obligación y, entre ellas la obligación alimenticia, la existencia de dos sujetos de derecho, fallecido uno de ellos, si la obligación es intuito personae, cuyo es el caso, no puede subsistir, porque faltará un elemento de su estructura. En este caso específico, el deudor. Se destruye como un edificio al que se la quitan sus cimientos. Se extingue.

20 OSSORIO, Manuel. Diccionario de ciencias jurídicas políticas y sociales. Editorial Heliasta S.R.L Buenos Aires,1992. pág.749.

21 COUTURE ETCHEVERRY, Eduardo Juan, Vocabulario jurídico. Español y latín con traducción e vocablos al francés italiano portugués inglés y alemán Editorial Metropolitana $4^{\mathrm{a}}$ edición corregida actualizada y ampliada. Buenos Aires, 2013. pág 700.

22 PEÑAILILlO AREVALO, Daniel. Obligaciones. Editorial Jurídica de Chile. Santiago, 2011. pág.27. 
En el fondo, se pierde el título que habilitó al alimentante para obtener una sentencia que declaraba la obligación alimenticia y, como el título era el antecedente para la adquisición del derecho, se extingue el derecho y la correlativa obligación. Y ello porque la obligación alimenticia es intiuto personae, y por ello intransmisible, además de personalísima. Es lo mismo que sucede con las obligaciones intuito personae cuya fuente es el contrato, tales como las que emanan del mandato, del contrato de trabajo, del de confección de obra y otras. Al fallecer el mandante, el trabajador, el artífice, los respectivos contratos terminan y como consecuencia de dicha terminación se extinguen las obligaciones que emanaban de ellos.

Llegamos a la misma conclusión, esto es que la obligación alimenticia se extingue por la muerte del alimentante en contra de quién se tenía título para demandar alimentos por interpretación del artículo 332 del Código Civil, en cuanto prescribe que los alimentos se entienden concedidos por toda la vida del alimentario, mientras subsistan las circunstancias que legitimaron la demanda. Debemos entender por circunstancias que legitimaron la demanda, la concurrencia de los requisitos de la obligación alimenticia, - capacidad económica, necesidad, título legal y ausencia de prohibición- requisitos que, constatados por el juez, determinaron el pronunciamiento de una sentencia declarativa de la obligación alimenticia. La muerte del alimentante es una modificación a dichas circunstancias, porque la necesidad que exista un alimentante en contra de quien se tiene título legal para demandar alimentos es un requisito de la obligación alimenticia, una circunstancia que legitimó la demanda. Faltando uno de los requisitos -circunstancias que legitimaron la demanda- los alimentos ya no se pueden entender concedidos por toda la vida del alimentario, porque esta consecuencia está prevista en el enunciado normativo para la hipótesis de que se mantengan los requisitos o circunstancias.

\section{MODO DE EXTINGUIR LA OBLIGACIÓN ALIMENTICIA.}

Establecido que la obligación alimenticia es personalísima, intransmisible, intuito personae y que, en consecuencia, se extingue cuando deja de existir la persona en contra de quién se tenía derecho a demandar alimentos por tener título, corresponde analizar cuál es, en este caso, el modo de extinguir de la misma.

La doctrina acerca del derecho de las obligaciones, incluidos los modos de extinguir, se construyó sobre la base de obligaciones contractuales de contenido patrimonial, especialmente la compraventa, y como tales 
transmisibles, por lo que la muerte de una de las partes de la obligación simplemente transmite el derecho y la obligación a sus herederos y no es considerada por la doctrina como modo de extinguir dichas obligaciones. No obstante, podemos concluir, a partir de la naturaleza, características $\mathrm{y}$ efectos de la obligación alimenticia que cuando fallece un acreedor o un deudor de una obligación personalísima e intransmisible, como lo es aquélla de dar alimentos, esta se extingue. En efecto, nuestro ordenamiento recoge el sistema clásico, de sucesión en la persona del difunto. En virtud de él, "el heredero es un continuador de la personalidad del causante, y por lo mismo no sólo adquiriría las cosas corporales contenidas en el patrimonio del causante, sino que lo reemplazaba "en todas las relaciones jurídicas activas y pasivamente transmisibles..."'23. Así se desprende de lo dispuesto tanto en el artículo 951 como en el 1097 de nuestro Código. "Queda claro, de esta forma, que los herederos, es decir los asignatarios a título universal, son los continuadores de la persona del difunto, y como tales son obligados al pago de las deudas que contrajo el causante, aun cuando sean superiores a lo que ellos reciben en la sucesión" 24 . Continúa el mismo autor: "No obstante, el principio de continuidad en la personal del causante en los herederos, no es absoluta"... "En muchos casos la muerte pone término a ciertas situaciones que afectaban al causante y respecto de ellas los herederos no pasan a ocupar el lugar que tenía el difunto". Por eso los artículos 951 y 1097 establecen que la sucesión es a título universal cuando se sucede al difunto en todos o una parte de sus derechos y obligaciones "transmisibles". "Esto deja claro que existen derechos y obligaciones que, si bien se encuentran en el patrimonio del causante, no son trasmisibles y que, por lo tanto, no pasan a sus herederos"25. Los profesores Domínguez, si bien no le atribuyen expresamente a la sucesión por causa de muerte la calidad de modo de extinguir las obligaciones, expresan que ella "no puede ser concebida solamente como modo de adquirir el dominio"26. Anteriormente en su obra habían afirmado que "el principio de la continuación tiene sus excepciones, que como Derecho Sucesorio dice relación con los derechos y obligaciones trasmisibles del causante, pero que la adquisición del activo y las obligaciones del pasivo se detienen allí donde el sucesor se enfrenta

23 ELORRIAGA DE BONIS, Ob. cit. pag. 13.

24 ELORRIAGA ob. cit. pág. 18.

25 Ibídem. pag 20.

26 DOMINGUEZ BENAVENTE, Ramón, DOMÍNGUEZ ÁGUILA, Ramón. Derecho sucesorio.Tomo I Editorial Jurídica de Chile. Santiago. 1998 pág. 134. 
a un derecho personalísimo o a un bien extrapatrimonial del causante..."27. Por su parte, Luis Claro Solar señala brevemente que hay obligaciones que por su naturaleza no se trasmiten, como son las que suponen una aptitud particular en la persona que debe cumplirlas ${ }^{28}$. Pablo Rodríguez va más allá y define la sucesión por causa de muerte no solo como modo de adquirir, sino que también como modo de extinguir las obligaciones ${ }^{29}$. Señala que es tal, "cuando ellas no pueden trasmitirse a los herederos ${ }^{30}$." Lo único que puede suceder con esas obligaciones intransmisibles es que ellas se extinguen. El modo de extinguir es la muerte.

Porque la obligación alimenticia es personalísima, intransmisible e intuito personae, no cabe sino concluir que ella se extingue cuando muere el alimentante, por lo que desde ese momento no se seguirán devengando pensiones de alimentos a favor del alimentario.

\section{CONCLUSIONES.}

1. Si bien el Código Civil establece en su artículo 334 que el derecho de pedir alimentos no puede transmitirse por causa de muerte, no existe una norma que resuelva si la obligación alimenticia es también intransmisible.

2. Para demandar alimentos se requiere tener título el que emana de la calidad de cónyuge y los parentescos que se señalan en el artículo 321 del Código Civil. En conscuencia, la obligación alimenticia es un efecto del estado civil en cuanto es atributo de la personalidad.

3. Los atributos de la personalidad se extinguen con la muerte del sujeto titular de los mismos.

4. Solo podemos demandar alimentos de las personas señaladas en el artículo 321 del Código Civil.

27 Idem. pág. 53.

28 CLARO SOLAR, Luis. Explicaciones de Derecho Civil y Comparado. Tomo XIII, ob.cit. p. 14.

29 Modo de adquirir gratuitamente el dominio del patrimonio de una persona cuya existencia legal se extinguido natural o presuntivamente y que consiste en el traspaso que a los herederos de todos sus derechos y obligaciones trasmisibles, que extingue los derechos y obligaciones intransmisibles, que es fuente de derechos personales para los legatarios de género y modo de adquirir el dominio de cosas singulares para los legatarios de especie o cuerpo cierto. (Rodríguez, 2002: Tomo I p. 16)

30 RODRIGUEZ GREZ, Ob. cit. pág. 16. 
5. Como consecuencia de lo señalado en los números 2,3 y 4 precedentes, podemos afirmar que la obligación alimenticia es personalísima e intuito personae.

6. Siendo la obligación alimenticia personalísima e intuito personae, es siempre intransmisible.

7. El modo de extinguir la obligación alimenticia es la muerte del deudor de alimentos.

\section{BIBLIOGRAFÍA.}

AGUIRRE VARGAS, Carlos. (1891) Obras jurídicas. Imprenta Gutemberg. Santiago.

BELLO, Andrés, (1932) Obras completas. Santiago, Editorial Nascimento, 1932.

CLARO SOLAR, Luis. Explicaciones de Derecho Civil y Comparado. Tomo XIII, "De la sucesión por causa de muerte" Santiago, 1940.

CLARO SOLAR, Luis. Explicaciones de Derecho Civil y Comparado. Tomo XV, "De la sucesión por causa de muerte" Santiago, 1942.

COUTURE ETCHEVERRY, Eduardo Juan, (2013) Vocabulario jurídico. Español y latín con traducción e vocablos al francés italiano portugués inglés y alemán Editorial Metropolitana $4^{\mathrm{a}}$ edición corregida actualizada y ampliada. Buenos Aires.

DOMINGUEZ BENAVENTE, Ramón, DOMÍNGUEZ ÁGUILA, Ramón. (1998) Derecho sucesorio. Editorial Jurídica de Chile. Santiago.

ELORRIAGA DE BONIS, Fabián, (2010) Derecho Sucesorio. Abelardo Perrot, Legal Publishing, Santiago.

GARRIDO CHACANA, Carlos. (2014) Derecho de Alimentos. Editorial Metropolitana. Santiago.

GUZMAN BRITO, Alejandro. (2008) La doble naturaleza de deuda hereditaria y asignación hereditaria forzosa de los alimentos debidos por ley a ciertas personas. En Revista Chilena de Derecho, Vol 35, $\mathrm{N}^{\circ} 2$. 
ORREGO ACUÑA, Juan Andrés. (2009) Los alimentos en el Derecho Chileno. Editorial Metropolitana. Santiago.

OSSORIO, Manuel. (1992) Diccionario de ciencias jurídicas políticas y sociales. Editorial Heliasta S.R.L Buenos Aires.

PACHECO, Máximo. (1976) Introducción al Derecho, Editorial Jurídica del Chile. Santiago.

PEÑAILILLO AREVALO, Daniel. (2011) Obligaciones. Editorial Jurídica de Chile. Santiago.

RODRIGUEZ GREZ, Pablo. (2002) Instituciones de Derecho sucesorio. Tomos I y II, Editorial Jurídica de Chile. Santiago.

SOMARRIVA UNDURRAGA Manuel, (1963) Derecho de Familia. Editorial Nascimento. Santiago.

SUAREZ FRANCO, Roberto, (1989) Derecho de Sucesiones, Temis. Bogotá.

VODANOVIC HAKLIKA, Antonio. (2004) Derecho de alimentos. Lexis Nexis. Santiago.

\section{JURISPRUDENCIA}

CORTE SUPREMA 27 de enero 2011. Recurso 6424/2010 "Rojas Palma con Hammer Krawczyk".

CORTE DE APELACIONES DE SANTIAGO. 22 de junio 2010. Recurso $3237 / 2009$. 